\title{
Tres cartas de Lorenzo Luzuriaga a Manuel Bartolomé Cossío
}

\author{
(Three letters from Lorenzo Luzuriaga \\ to Manuel Bartolomé Cossío)
}

\author{
Eugenio OTERO URTAZA \\ Universidade de Santiago de Compostela
}

\begin{abstract}
En memoria de Herminio Barreiro
RESUMO: Neste artigo amosanse tres cartas, ata agora inéditas, que Lorenzo Luzuriaga escribiu a Manuel B.Cossío entre 1907 e 1920. Este breve epistolario descobre como se iniciou a relación entre ambos educadores e as impresións que lle produciron a Luzuriaga as súas primeiras viaxes por Europa, así como descobre cales eran as súas inquedanzas políticas, nos tempos previos á fundación da Revista de Pedagogía e a súa adscrición á Liga Internacional de Educación Nova.

PALABRAS CHAVE: epistolarios educativos; Institución Libre de Enseñanza; Escola Nova: Lorenzo Luzuriaga; Manuel B. Cossío.

ABSTRACT: The article presents three unpublished letters from Lorenzo Luzuriaga to Manuel B. Cossío, dating from the period 1907-1920. The letters reveal how the relationship between the two began, Luzuriaga's impressions from his first trips around Europe, and his political ideas prior to the foundation of Revista de Pedagogía and his membership of the New Education Fellowship.
\end{abstract}

KEYWORDS: educational letters; Free Institute of Education; New School; Lorenzo Luzuriaga; Manuel B. Cossío.

Entre os moitos discípulos de Manuel Bartolomé Cossío, ningún tivo unha vinculación tan forte co movemento da Escola Nova como Lorenzo Luzuriaga que chegou a formar parte do Comité Executivo da Liga Internacional de Educación Nova. E desde logo é o impulsor dunha das revistas máis destacadas desta organización, a máis importante en lingua castelá e que marcou, como di Herminio Barreiro "un fito no proceso de renovación pedagóxica e cultural" do primeiro terzo do século XX, porque ademais, o movemento da Escola Nova, como un 
fenómeno transnacional e transformador, non podería entenderse sen a Revista de Pedagogía que el fundou en 1922.

Luzuriaga non só foi un extraordinario pedagogo e un dos máis importantes discípulos de Cossío. Foi tamén unha peza indispensable nun movemento de alcance mundial que transformou ao final da Primeira Guerra Mundial as ideas sobre a educación xeral e pública; a que atende a toda a cidadanía sen distinción de clases sociais, sexo, relixión, poder económico das familias ou capacidade intelectual ou física dos escolares. É quizais quen mellor documentou o movemento da Escola Nova, o que foi capaz de comparar o que ocorría en distintos países e continentes, un dos que máis traballou en combinar as ideas de "escola activa" e "escola unificada" e concibir un plan para levar adiante unha educación para todos. O conxunto de ideas que nos deixou sobre o movemento da Escola Nova, como unha síntese que podemos considerar superior a textos dos autores principais e aos relatos dos froitos de cada país, atópanse orixinalmente en castelán, grazas aos libros e artigos que nos deixou analizando o fenómeno desde unha perspectiva internacional. Sen dúbida en Alemaña, Suecia ou nos Estados Unidos, xurdiron ideas extraordinarias que foron emuladas polos demais países do mundo, pero neses países non se preocuparon polo que se estaba desenvolvendo noutros, ou pola orixinalidade dalgunhas propostas locais ou rexionais; e, en todo caso, parece que en ningún deles temos libros de síntese, de época, sobre o que estaba a pasar no mundo coa Escola Nova, que presentaran un relato de conxunto e actual sobre a Escola Nova, conforme o fenómeno se producía, como o fixo Lorenzo Luzuriaga.

É unha das vertentes que o fan tan importante, tan necesario; porque se hoxe queremos ir a documentos do seu tempo, ás fontes primarias en castelán e as primeiras traducións, para entender o que foi este movemento na súa dimensión de transnacionalidade, non hai nada mellor que os libros que escribiu Lorenzo Luzuriaga.

Herminio Barreiro lémbranos cales foron algunhas desas obras de exposición doutrinal máis importantes que escribiu o pedagogo manchego: La Escuela Unificada (1922), Las Escuelas Nuevas (1923), Escuelas de Ensayo y Reforma (1924), Escuelas Activas (1925), Concepto y desarrollo de la Nueva Educación (1925) y La Educación Nueva (1927). Son traballos de recapitulación sobre procesos escolares extraordinariamente creativos no seu contexto histórico, que falan de moitas escolas do mundo occidental, que non teñen parangón noutras culturas. Non se pode discutir a importancia do pensamento de Dewey, das iniciativas de Ellen Key, da idea da escola do traballo de Kerschensteiner. Pero neses países é dificilísimo atopar un libro no primeiro terzo do século XX que fale sobre o que nese tempo se facía en España ou nas repúblicas iberoamericanas. Para realizar un estudo comparado internacional do movemento da Escola Nova, o traballo de Luzuriaga é aínda hoxe admirable; e coñecer como chegou a realizar esta tarefa regálanos ás veces novos documentos que permiten afondar na súa 
biografía. Así, poder recuperar hoxe, en 2021, algunhas pinceladas da súa vida e preocupacións a través de tres cartas inéditas, nun número de Sarmiento que trata sobre o que foi a Escola Nova, é sen dúbida un acontecemento moi feliz.

Lorenzo Luzuriaga nacera en Valdepeñas o 29 de outubro de 1889, nunha familia de mestres, e moi novo trasladouse a Madrid tras o falecemento do seu pai. Alumno da Escola Normal Central, alí terminou os seus estudos en 1907, e debía ter xa entón moitas inquietudes para, sen cumprir aínda 18 anos, dirixirse a Cossío en procura de orientación. A carta de 1907 é un documento de moito interese; é a primeira vez que Luzuriaga se pon en contacto con Cossío e faino a instancias e recomendación de Agustín Sardá (1836-1913) que era un destacado institucionista, compañeiro de Giner, profesor da Institución Libre de Enseñanza (ILE) e membro da súa Xunta Directiva entre 1888 e 1913, pero cun perfil político moi acentuado. A carta é respectuosa e formal, como corresponde a un mozo aprendiz de mestre que por primeira vez se dirixe a unha alta autoridade demandando consello e asesoramento, e foille respondida como apunta a $C$ que aparece posta na parte superior a esquerda desta carta.

Acabábase de crear a JAE e quería Luzuriaga formarse no estranxeiro polo que fixo unha solicitude datada o 5 de agosto de 1907, cando aínda estaba pendente de terminar os seus estudos. Convén deterse nesta instancia, onde Luzuriaga fai unha longa disertación para xustificar a súa petición que non se vai repetir posteriormente, xa que o conxunto de méritos alegados nesta primeira ocasión xa non necesitaría desa reflexión inicial:

Lo limitado de nuestra enseñanza oficial en lo que se refiere a la adquisición de conocimientos para la educación de los alumnos, debido, sin duda, a la mucha extensión y poca intensión de los programas oficiales, y lo que es más importante, a la mala organización de nuestra enseñanza como lo han notado ya ilustres pedagogos como Azcárate, Giner, Altamira, Posada, etc., añadido al poco ambiente pedagógico que aquí, en general, se respira a pesar de los esfuerzos valiosos y laudatorios de ciertas instituciones y personalidades pedagógicas, hace necesario acudir a otros pueblos, en los que esta atmósfera pedagógica sea más amplia y sus horizontes más extensos para que el que vaya allí extienda su campo pedagógico y se oriente en un sentido determinado. ${ }^{1}$

Esta primeira solicitude, na que pedía ir a Francia, Bélxica e a unha parte de Suíza, foille denegada. A Cossío debeulle caer moi ben aquel mozo estudoso porque o acolleu como alumno-mestre na ILE e presentoulle a Giner, e entre 1908 e 1912 estivo a traballar con eles na escola e participou nas colonias escolares de vacacións que organizaba o Museo Pedagóxico ${ }^{2}$ e seguramente o orientaron cara

\footnotetext{
${ }^{1}$ Residencia de Estudiantes (Madrid). Archivo JAE. Leg. 89/399.

2 Para contextualizar estas cartas de Cossío a Luzuriaga, utilizamos o libro de Herminio Barreiro, Lorenzo Luzuriaga y la renovación educativa en España (1889-1936), (Sada, A Coruña: Ediciós do Castro, 1989) 107-123. A maior parte das referencias que facemos están recollidas dese volume. Noutros casos que a afirmación o require, aportamos outras fontes complementarias que indicamos en nota
} 
á pedagoxía alemá. Ao mesmo tempo empezou a visitar de maneira continuada a Biblioteca do Museo Pedagógico e aprendeu alemán até o punto que en 1911 xa publicaría a súa primeira tradución: Kant, Pestalozzi e Goethe: Sobre educación, que sairía na editorial Jorro. Tras acabar os seus estudos na Escola Superior do Maxisterio na que ingresara en 1909, foi nomeado inspector de Primeiro Ensino da zona de Xinzo de Limia (Ourense) por R.O. do 16 de agosto de 1912. É un ano esencial na súa vida porque tamén casou con María Luisa Navarro, que coñecera na devandita Escola. Por R.O de 5 de marzo de 1913 foi nomeado inspector da provincia de Guadalajara. Quería estar preto de Madrid e regresar ao seu traballo na Biblioteca do Museo Pedagógico. Nese tempo Luzuriaga xa tiña detrás de si non só experiencia profesional senón tamén un fondo de publicacións moi estimable. Traducira a Pestalozzi ${ }^{3}$ e a Herbart, ${ }^{4}$ e incluso publicou o seu primeiro libro: Direcciones actuales de la Pedagogía en Alemania $^{5}$, e colaboraba cos cursos de vacacións para estranxeiros que organizaba o Ministerio de Instrución Pública.

O 20 de maio de 1909 reiterou a súa solicitude de bolsa a JAE. Foille concedida o 8 de setembro, pouco antes de cumprir vinte anos, para estudar a escola primaria en Alemaña e Suiza, ${ }^{6}$ pero renunciou entón a marchar, aprazándoa ata 1913. Saíu o 23 de novembro dese ano para Berlín para traballar sobre a estatística da Instrución Primaria na König Preuss Auskunftsstelle für Schulwesen, onde traballou baixo a dirección de Kulluich por recomendación de Castillejo. ${ }^{7}$ Continuou a súa pensión en 1914, trasladándose a Jena, e dispúñase a asistir aos cursos de verán de Wilhelm Rein cando o estoupido da Guerra o obrigou a interromper os seus traballos e regresar a España a finais de agosto. Foi nesa viaxe cando coñeceu a obra de Tews, Kerschensteiner e Natorp, iniciando unha xeira de publicacións periódicas coa revista Inspección de Primera Enseñanza (Boletín Mensual da Asociación Nacional de Inspectores) así como co Boletín de la Institución Libre de Enseñanza (BILE) nos que escribiu moitas notas e recensións que dan conta do proveito da súa estadía.

Ao seu regreso a Madrid, co conflito europeo iniciado, sucédense feitos que reafirmaron a súa xeración, a Xeración de 1914. O coñecido discurso de Ortega no Teatro da Comedia o 24 de maio dese ano, "Vieja y nueva política", deu como consecuencia a creación da Liga de Educación Política á que se adscribiu, así como participou no centro ateneístico e formativo Escola Nova de Núñez de Arenas.

\footnotetext{
${ }^{3}$ J.H. Pestalozzi: Cómo Gertrudis enseña á sus hijos (con prólogo de Luis de Zulueta). (Madrid: Cristóbal Ruíz, 1912) 277 pp.

${ }^{4}$ J.F. Herbart: Pedagogía General derivada del fin de la educación. (Madrid: La Lectura, 1914) 283 pp.

${ }^{5}$ Foi publicado pola "Librería Nacional y extranjera", e aínda que non consta ano de edición, saíu do prelo posiblemente antes de 1914.

${ }^{6}$ Conforme escrito remitido polo Reitor da Universidade de Madrid, de data 28 de maio de 1909, Luzuriaga presentou unha memoria: "La educación y la escuela primaria en Alemania y Suiza", así como un traballo que titulaba "Manuel Kant. Sobre Pedagogía”. Archivo JAE. Leg. 89/399.

${ }^{7}$ T. Marín Eced. Innovadores de la educación en España (Becarios de la Junta para Ampliación de estudios). (Cuenca: Servicio de Publicaciones de Castilla-La Mancha, 1991) 178.
} 


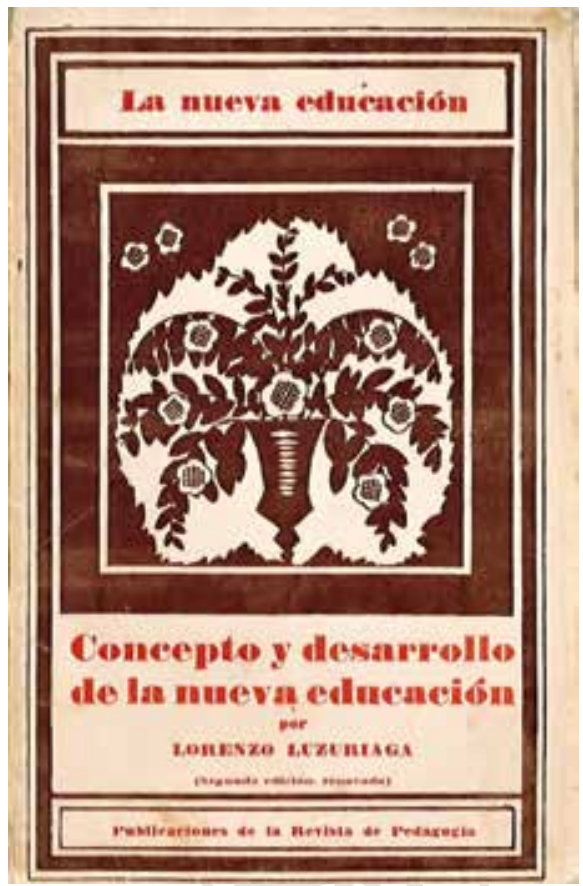

Portada do libro do que é autor Lorenzo Luzuriaga publicado en 1925 na colección Publicaciones de la Revista de Pedagogía.

Porén estas dúas adscricións, filosófica e política, non deixan en segundo plano a tarefa educativa na que está inmerso e que o vinculan estreitamente coa ILE. O 18 de febreiro de 1915 ao finar Francisco Giner de los Ríos, Cossío sumiuse nun gran desacougo mentres Luzuriaga revisa a súa obra La Enseñanza Primaria en España, que acadaría unha segunda edición moi enriquecida coas súas achegas. ${ }^{8}$ A súa relación con Cossío é xa tan forte que por unha R.O. do 31 de decembro de 1915 foi nomeado inspector agregado ao Museo Pedagógico Nacional.

A segunda carta é breve, e está motivada porque Cossío solicitáralle o enderezo de Salvador de Madariaga en Inglaterra, que lle proporcionou Luís Araquistáin. Madariaga permanecía en Surrey, ao servizo do goberno británico, para quen escribía textos de propaganda antixermánica. ${ }^{9}$ Araquistáin e Luzuriaga estaban entón afiliados ao Partido Socialista, e a carta amosa un breve apuntamento da súa radicalización política que o levará durante un breve período a militar no Partido

\footnotetext{
${ }^{8}$ M.B. Cossío. La enseñanza primaria en España, $2^{\mathrm{a}}$ edición revisada por Lorenzo Luzuriaga. (Madrid: Museo Pedagógico Nacional, 1915).

${ }^{9}$ Salvador de Madariaga casara en 1912 con Constance Helen Margaret Archibald (1878-1970), historiadora escocesa, nada en Glasgow.
} 
Comunista, tras a recente e impresionante Revolución Rusa que emerxía como un gran poder obreiro. Os tres eran membros da Liga de Educación Política e por tanto membros da Xeración de 1914, e cada un, ao seu modo, recibira a influencia de Ortega. E a nota de Araquistáin leva ademais o membrete de España, a revista emblemática que representa os intereses intelectuais e políticos daquela xeración. ${ }^{10}$

Rematada a Guerra, en 1919, Luzuriaga solicitou a reactivación dos tres meses da súa pensión que non puidera gozar, pedindo que os seus estudos puidesen facerse extensivos a Francia e Inglaterra, e non só a Alemaña, que fora o país que visitara en 1914. Na súa solicitude sinala que ao "reanudarse poco a poco la vida civil en los pueblos beligerantes", desexa facer estudos cos problemas da postguerra, comparando como están reorganizando eses países o seus sistemas nacionais de educación, especialmente en Inglaterra. ${ }^{11}$ A solicitude foi denegada polo que volveu pedila ao ano seguinte con data 14 de abril, que si lle foi concedida, coa finalidade de visitar os tres países e estudar a reconstitución pedagóxica tras a guerra. Visitou así París, Londres e Berlín e fíxose unha composición moi exacta do significado que tiña o sistema educativo de cada un deles, o que seguramente influíu moito no cadro internacional que compuxo para outros estudos comparativos posteriores. Saíu para París en novembro de 1920 e as súas notas de viaxe apareceron no xornal El Sol no mes de xuño de 1921. No Reino Unido estudou principalmente a aplicación da lei Fisher e, ademais, visitou a Worker's Educational Association, a World Association for Adult Education e a Teacher's Guild.

As tres cartas amosan a un Luzuriaga mozo, anterior a súa dedicación á Revista de Pedagogía que está construíndo o armazón do seu pensamento cos fíos das súas aprendizaxes nas viaxes polo estranxeiro. Resulta cando menos extraordinario no estudo das súas concepcións educativas o enorme peso que ten a pedagoxía alemá. As ideas de Natorp que tanto compartirá con Ortega e mesmamente con Domingo Barnés, e especialmente a Einheitschule [Escola Unificada], que será o eixo do seu discurso no relatorio que espuxo como membro da Escola Nova de Madrid, na ponencia sobre o Programa Mínimo do XI Congreso Ordinario do PSOE en 1918, que, en liñas xerais, será o que defendería para a reforma xeral do sistema educativo na República en 1931, está xa en xermolo á volta da primeira viaxe.

Contrasta esta admiración pola pedagoxía alemá co rexeitamento frontal a súa política; e o contido entusiasmo, aínda que pouco esperanzado, que lle produce o que está a ocorrer en Inglaterra. É o tempo no que vai ter un breve fervor pola Revolución Rusa, cando, como noutros países de Europa, o socialismo sofre a

\footnotetext{
${ }^{10}$ A revista España. Semanario de la vida nacional, saíu á luz o 29 de xaneiro de 1915. Foi fundada por José Ortega y Gasset, pero Luis Araquistáin foi o seu director entre 1916 e 1923. Era unha publicación progresista e anglófila, na que escribiu unha boa parte da intelectualidade da época, e estaba claramente aliñada co bando aliado. Vid. Luis Araquistáin. La revista "España” y el Estado liberal. Estudio preliminar Ángeles Barrio. (Santander: Publicaciones de la Universidad de Cantabria, 2001).

${ }^{11}$ Instancia datada o 25 de febreiro de 1919, dirixida ao presidente da JAE. Archivo JAE. Leg. 89/399.
} 
escisión dos 'terceiristas' que marchan para a III Internacional, afiliándose ao Partido Comunista. No seu caso foi unha viaxe de ida e volta. A terceira carta prefigura xa ese salto con varios meses de antelación porque a escisión levouse a cabo o 13 de abril de 1921. Posiblemente eran confidencias dos seus pensamentos que non facía sempre aos seus compañeiros, pero a Cossío podían confiárselle sentimentos moi persoais e íntimos.

Temos así, con estas tres cartas, unha nova pincelada ao coñecemento da biografía e pensamento de Lorenzo Luzuriaga. Esta correspondencia consérvase na Biblioteca da Academia da Historia de Madrid, e a revista Sarmiento agradece á Fundación Francisco Giner de los Ríos, propietaria destes valiosísimos fondos documentais, a autorización para poder publicalas na súa integridade. ${ }^{12}$

\section{1.- Carta datada 010 de Abril de 1907}

Mi muy respetable señor:

El Sr. Director de la Escuela Central Normal Central, D. Agustín Sardá, nos manifestó un día que uno de los fines que perseguía el Museo que V. tan dignamente dirige, era dar opinión a las consultas que se le dirigen y que si alguna vez nos ocurriera consultar algo, lo hiciéramos a V. con la esperanza de que no nos veríamos defraudados.

Acordándome de esto me atrevo a molestarle para que me dé su opinión, si es que así le place sobre este asunto:

Quisiera ampliar los estudios de Pedagogía recibidos en esta Normal y con este objeto le agradecería muchísimo me indicara textos, ya castellanos, ya franceses, que ese Museo posee y al mismo tiempo las que para este objeto no posea siendo de fácil adquisición.

Como le he manifestado lo que me propongo es seguir estudiando la Pedagogía en un curso que pudiera llamarse de Estudios superiores, enlazando los textos según un método progresivo y racional.

Creyendo ser complacido por quien tanto bien hace por la cultura, le pido mil perdones y se despide de V. su aftmo. s.s. q. 1. b. s. m.

Lorenzo Luzuriaga

Madrid, 10-IV-907

\section{2.- Carta datada 018 de novembro de 1918.}

Querido Sr. Cossío:

\footnotetext{
${ }^{12}$ Biblioteca da Real Academia de la Historia (Madrid). Fondo documental da Fundación Francisco Giner de los Ríos. Carta datada o 10/IV/1907, leg. 49-1017/3. Carta datada o 12/XI/1918, leg. 45863/2. Carta non datada [outubro de 1920], leg. 46-895/2.
} 
Al fin Araquistáin se ha acordado de enviarme las señas de Madariaga, que le incluyo en esta. Siento mucho el retraso, pero ya sabe que es involuntario por mi parte.

Esta tarde vamos a tratar algunos amigos de manifestarnos por las calles; es una vergüenza que a estas horas no se haya hecho nada en Madrid públicamente por la victoria de los aliados. No sé donde acabaremos; pero es necesario movilizarse.

Suyo

L. Luzuriaga

[Nota de Luis Araquistáin que se adxunta]

\section{ESPAÑA/ Prado 11/ Madrid}

Amigo Luzuriaga

Aquí va la dirección de Salvador de Madariaga:

Fairview, Portsmouth Road,

Esher, Surrey, Inglaterra.

Perdone que mi poca memoria haya dilatado tanto tiempo este envío.

Araquistáin

\section{3.- Carta sen data [outubro? de 1920]}

\section{8, Grenville Street/ Brunswick Square/ W.C. 1}

\section{Querido Señor Cossío}

Desde que volví de Madrid tengo todos los días el propósito de escribirle para decirle algo de mi viaje; pero ya sabe V. lo que supone para un hombre su primera salida a París y a Londres y se hará V. cargo de mi silencio. Realmente he emprendido este viaje con más emoción que el de Alemania; a medida que se va haciendo uno más viejo se comprenden más las cosas y se tiene más respeto por ellas. Me puse pues en marcha casi como un peregrino a Tierra Santa y si he de decirle la verdad, según van pasando los días voy perdiendo más ese sentimiento de respeto con que empecé el viaje.

Seguramente encontrará V. esto precipitado y pretencioso; pero es la expresión real de mi estado de ánimo. En el poco tiempo que he estado en París, como el que llevo en Londres, he visto en la vida social y política más injusticias y opresiones que espíritu de moralidad y deseo de hacer bien las cosas. No hay más problema que el económico ni más programa político que acabar con el único intento verdadero para desterrar esta injusticia universal: Rusia. En tanto, los niños de las escuelas públicas de París y Londres van con trajes andrajosos y sucios, y con caras enfermizas, de hambre. Y en contraste con esto, un lujo cada vez más 
ostentoso y provocativo. Ahora mismo hay aquí más de medio millón de hombres en huelga porque no les suben 2 chelines en su jornal, en tanto que las empresas industriales reparten dividendos tan altos como cuando hacían municiones para la guerra.

En cuanto la parte pedagógica, mi impresión es que las cosas siguen como antes de la guerra. Cuando se aplique plenamente la ley Fisher estas cambiarán en poco; pero lo fundamental no variará hasta que ocurran cambios sociales más profundos. He visto escuelas elementales y de adultos, e iré estos días a Oxford y a Harrow. Hablé con Mr. Twentymass [sic $]^{13}$ y con los directores del Teacher's Guild. Como es natural estas impresiones de ahora necesitan ser contrastadas con más tiempo. Aún me queda por ver muchas cosas y gentes, antes de salir para Alemania en las dos semanas que tengo por delante.

Aquí está Beruete ${ }^{14}$ preparando la exposición española de pintura en la Royal Academy; parece que está muy bien, por lo que puede juzgar un profano. Tienen mucho sitio para colgar las cosas, y realmente las han puesto bien. Creo que producirán buena impresión, sobre todo los Grecos y Goyas que traen.

No vea, Sr. Cossío, en lo que he dicho nada de desamor o desatención a este pueblo. Inglaterra despierta siempre una curiosidad enorme, y en muchas cosas ha rebasado a las ideas que por las lecturas me había formando de ella. Pero la situación social es absolutamente injustificada e injustificable; las cosas se precipitan cada vez con mayor rapidez, y no creo que haya nadie capaz de detenerlas.

Por María Luisa he sabido de Vs. Veremos que experiencias pasan Vs. con esos chicos un tanto selváticos, sobre todo el pequeño. Como sé las cosas que tiene $\mathrm{V}$. que hacer le excuso de escribirme. Pongo las señas en esta solo por si necesitan de mí algo. Como V. comprenderá no pierdo de vista en este viaje los trabajos posibles para el Museo. Un afectuoso saludo de L. Luzuriaga

\section{Bibliografía}

Araquistain, Luís. La revista "España” y el Estado liberal. Estudio preliminar Ángeles Barrio. (Santander: Publicaciones de la Universidad de Cantabria, 2001).

\footnotetext{
${ }^{13}$ Aínda que fixen xestións para tratar de coñecer o significado desta verba, non cheguei a atopar a ninguén que puidera darme unha explicación dun apelido, se realmente é apelido e se refire a unha persoa, tan singular e raro en lingua inglesa. Coido que esta cuestión tería dado para unha longa conversa entre Herminio e eu, sobre as sorpresas insolubles que as veces aparecen nos epistolarios.

${ }^{14}$ Aureliano de Beruete Moret (1876-1922). Director do Museo do Prado e fillo do pintor Aureliano Beruete (1845-1912). Este dato permite datar a carta a finais de outubro de 1920, xa que a exposición Exhibition Spanish Painting na Royal Academy, celebrouse entre o 3 de novembro de 1920 e o 15 de xaneiro de 1921. Vid., Exhibition of Spanish paintings at the Royal Academy of Arts, November 1920-January 1921. (London: Royal Academy of Arts (Great Britain), 1920).
} 
Barreiro, Herminio. Lorenzo Luzuriaga y la renovación educativa en España (1889-1936), (Sada, A Coruña: Ediciós do Castro, 1989).

Cossío, Manuel Bartolome. La enseñanza primaria en España, $2^{\text {a }}$ edición revisada por Lorenzo Luzuriaga. (Madrid: Museo Pedagógico Nacional, 1915).

Exhibition of Spanish paintings at the Royal Academy of Arts, November 1920-January 1921. (London: Royal Academy of Arts (Great Britain), 1920).

Herbart, Johann Friedrich. Pedagogía General derivada del fin de la educación. (Madrid: La Lectura, 1914).

Marín Eced, Teresa. Innovadores de la educación en España (Becarios de la Junta para Ampliación de estudios). (Cuenca: Servicio de Publicaciones de Castilla-La Mancha, 1991).

Pestalozzi, Johann Heinrich. Cómo Gertrudis enseña á sus hijos (con prólogo de Luis de Zulueta). (Madrid: Cristóbal Ruíz, 1912). 